\title{
Reflexões sobre a inclusão de deficientes visuais no contexto universitário
}

\section{Reflections on the inclusion of visually impaired people in the university context}

Reflexiones sobre la inclusión de las personas con discapacidad visual en el contexto universitario

Gabrielle Oliveira Dos Santos Anchieta ${ }^{1}$ ORCID: https://orcid.org/0000-0003-1160-569X Universidade Columbia Del Paraguay, Paraguai E-mail: gabbiosantos@yahoo.com

Pedro Carlos Pereira ${ }^{2}$

ORCID: https://orcid.org/0000-0003-4646-0080 Universidade Federal Rural do Rio de Janeiro, Brasil Universidade Columbia Del Paraguay, Paraguai E-mail: pecape@ig.com.br

Marta Martins De Oliveira ORCID: https://orcid.org/0000-0002-2806-6496 Universidade Columbia Del Paraguay, Paraguai E-mail: martammjjfilhos@hotmail.com

José Luis Monteiro Da Conceição ${ }^{3}$ ORCID: https://orcid.org/0000-0003-3496-8311 Grupo de Pesquisa Formação de Professores, Saberes e Práticas Educativas no Campo da Pesquisa Intervenção, Brasil E-mail: luisuneb1@hotmail.com

Breno Giovanni Adaid-Castro ${ }^{4}$ ORCID: https://orcid.org/0000-0002-9856-4263 Universidade FUMEC, Brasi Universidade de Brasília, Brasil University of Oregon, Estados Unidos E-mail: Brenoadaid@gmail.com

Eliane Dos Santos Macedo Oliveira ORCID: https://orcid.org/0000-0002-7523-6558 Colégio Estadual Rancho Alegre, Brasil

E-mail: esmacedo879@gmail.com

Camila Mazzetto Paes Seo

ORCID: https://orcid.org/0000-0002-7295-1222 Pedagoga e Pós-graduada em Psicopedagogia, Neuropsicopedagogia e AEE, Brasil E-mail: camila_mazzetto@hotmail.com

Valdir Ameida Lopes ${ }^{7}$

ORCID: https://orcid.org/0000-0003-0567-391X Universidade Columbia Del Paraguay, Paraguai E-mail: pr.lopes.4@hotmail.com

Evaldo Freires De Carvalho ORCID: https://orcid.org/0000-0002-4539-8441 Universidade Columbia Del Paraguay, Paraguai E-mail: evaldofreires@hotmail.com

\footnotetext{
${ }^{1}$ Mestranda em Ciências da Educação pela Universidade Columbia Del Paraguay/Instituto IDEIA- Paraguai

${ }^{2}$ Professor Adjunto da Universidade Federal Rural do Rio de Janeiro/Brasil e Professor Colaborador do Programa de Pós-Graduação da Universidade Columbia Del Paraguay/Instituto IDEIA- Paraguai

${ }^{3}$ Mestre em Educação. Pedagogo e Licenciado em Letras. Pesquisador do Grupo Laboratório de Pesquisas e Políticas Linguísticas, Interação e Desenvolvimento Humano- LIDAH. Integrante do Grupo de Pesquisa Formação de Professores, Saberes e Práticas Educativas no Campo da Pesquisa Intervenção

${ }^{4}$ Professor Doutor - IESB, Universidade FUMEC - Campus Cruzeiro, Universidade de Brasília, University of Oregon

${ }^{5}$ Mestra em Educação - Unioeste Paraná - Diretora do Colégio Estadual Rancho Alegre

${ }^{6}$ Pedagoga e Pós-graduada em Psicopedagogia, Neuropsicopedagogia e AEE

${ }^{7}$ Mestrando em Ciências Jurídicas pela Universidad Columbia Del Paraguay - Instituto IDEIA - Paraguai
} 


\title{
Resumo
}

A inclusão de alunos deficientes visuais, parcial ou total, é uma realidade no processo educacional brasileiro. Esse assunto tomou força no Brasil e no mundo por volta de 1990 e é um assunto pertinente em discussões e debates sobre educação inclusiva. A Educação é fundamental para que o homem garanta a sua existência a partir das mudanças naturais. Ela é responsável pelo desenvolvimento da produção do saber e da cultura. A partir da identificação dos elementos culturais e também da descoberta de novas formas para facilitar a assimilação desses elementos, a Educação passa a ser uma exigência. No que diz respeito à pessoa com deficiência, a Educação constitui uma questão fundamental no mundo e tem sido objeto de inúmeros debates e reflexões. Incluir na educação básica a pessoa com deficiência visual merece um olhar mais atento, devido a possível rejeição do grupo para com essa pessoa, e assim, não podemos trabalhar uma inclusão onde apenas colocamos essa pessoa em meio aos outros, e deixamos fluir naturalmente sua interação. Faz-se necessário um trabalho consistente e responsável para que a inclusão aconteça efetivamente. Para tanto, propõem-se em analisar questões peculiares ligadas a esse grupo, de modo a garantir maior efetividade nessa inclusão, ou interação. Devemos garantir a equidade de todos pois dessa forma teremos uma educação justa e verdadeira, atendendo aos anseios de todos os indivíduos envolvidos no processo de ensinoaprendizagem. Apresentamos no artigo reflexões sobre o tema a partir do contexto histórico-sócio-cultural da cegueira, a legislação vigente no Brasil e de alguns aspectos do processo inclusivo dos deficientes visuais na Educação Universitária. Para tanto realizou-se uma revisão literária dos estudos apresentados em revistas especializadas, periódicos e trabalhos acadêmicos acerca do tema e de seus aspectos relevantes a sociedade, bem como, em bases de dados como Pubmed, Scielo, Google Scholar, bibliotecas virtuais, entre outras.

Palavras-chave: Ensino; Deficiência visual e cegueira; Educação especial e inclusão; Legislação da Educação Especial.

\begin{abstract}
The inclusion of partially or totally visually impaired students is a reality in the Brazilian educational process. This issue gained momentum in Brazil and around the world around 1990 and is a relevant issue in discussions and debates on inclusive education. Education is fundamental for man to guarantee his existence based on natural changes. She is responsible for developing the production of knowledge and culture. From the identification of cultural elements and also the discovery of new ways to facilitate the assimilation of these elements, Education becomes a requirement. With regard to people with disabilities, Education is a fundamental issue in the world and has been the object of countless debates and reflections. Including the visually impaired person in basic education deserves a closer look, due to the possible rejection of the group towards this person, and thus, we cannot work an inclusion where we only place this person among others, and let their interaction flow naturally . Consistent and responsible work is needed for inclusion to happen effectively. Therefore, they propose to analyze specific issues related to this group, in order to ensure greater effectiveness in this inclusion, or interaction. We must guarantee equity for all, because in this way we will have a fair and true education, meeting the wishes of all individuals involved in the teaching-learning process. In the article, we present reflections on the theme from the historical-socio-cultural context of blindness, the current legislation in Brazil and some aspects of the inclusive process of the visually impaired in University Education. Therefore, a literary review of the studies presented in specialized journals, periodicals and academic papers on the subject and its aspects relevant to society was carried out, as well as in databases such as Pubmed, Scielo, Google Scholar, virtual libraries, among others.
\end{abstract}

Keywords: Teaching; Visual impairment and blindness; Special education and inclusion; Special Education Legislation.

\section{Resumen}

La inclusión escolar de estudiantes con discapacidad visual, parcial o totalmente, es una realidad en el proceso educativo brasileño. Este tema ganó impulso en Brasil y en todo el mundo alrededor de 1990 y es un tema relevante en las discusiones y debates sobre educación inclusiva. La educación es fundamental para que el hombre garantice su existencia a partir de los cambios naturales. Es la responsable de desarrollar la producción de conocimiento y cultura. Desde la identificación de elementos culturales y también el descubrimiento de nuevas formas de facilitar la asimilación de estos elementos, la Educación se convierte en un requisito. En cuanto a las personas con discapacidad, la Educación es un tema fundamental en el mundo y ha sido objeto de innumerables debates y reflexiones. Incluir a la persona con discapacidad visual en la educación básica merece una mirada más cercana, debido al posible rechazo del grupo hacia esta persona, por lo que no podemos trabajar una inclusión donde solo ubiquemos a esta persona entre otras, y dejemos que su interacción fluya con naturalidad. Es necesario un trabajo constante y responsable para que la inclusión se lleve a cabo de manera eficaz. Por ello, proponen analizar temas específicos relacionados con este grupo, con el fin de asegurar una mayor efectividad en esta inclusión o interacción. Debemos garantizar la equidad para todos, porque de esta manera tendremos una educación justa y verdadera, cumpliendo los deseos de todas las personas involucradas en el proceso de enseñanza-aprendizaje. En el artículo presentamos reflexiones sobre el tema desde el contexto histórico-sociocultural de la ceguera, la legislación vigente en Brasil y algunos aspectos del proceso inclusivo de los discapacitados visuales en la Educación Básica. Por ello, se realizó una revisión literaria de los estudios presentados en revistas especializadas, publicaciones periódicas y trabajos académicos sobre el tema y sus 
aspectos relevantes para la sociedad, así como en bases de datos como Pubmed, Scielo, Google Scholar, bibliotecas virtuales, entre otras.

Palabras clave: Enseñanza; Discapacidad visual y ceguera; Educación especial e inclusión escolar; Legislación de educación especial.

\section{Introdução}

A Organização Mundial da Saúde (OMS), segundo Santos (2004), define cegueira como a perda total ou parcial da capacidade de ver após todas as correções possíveis que acarrete prejuízo em coletar informações. (Santos, 2004 apud Parnof, 2010)

Segundo a Fundação Dorina Nowill, pesquisas e estudos apontam que 3,5\% da população brasileira declara-se com alguma deficiência visual. A OMS, divulgou em estudo realizado que 6,5 milhões de pessoas possuem alguma deficiência visual no Brasil. Dentre elas, uma média de 530.000 atingiram a cegueira total. (Dorina, 2021)

A ocorrência da cegueira no contexto histórico tem seus diferentes significados e estão inseridos na própria história da humanidade, assim como foi marcada por sentimento de rejeição, preconceito, intolerância, religiosidade e ignorância. Os conceitos dados por Platão e Aristóteles sobre a cegueira, pelo aspecto ideológico na Grécia Antiga, quando se constituiu a caracterização dos cinco sentidos, é considerado até os dias atuais. (Classen, 1993 apud Martins, 2011) O trovador cego Homero, acatado como escritor de Ilíada e Odisseia, morreu na miséria recitando seus versos pelas ruas da cidade. A ausência da visão para os gregos tomava uma conotação negativa, empunhando-a aos sacrilégios e aos adúlteros. No entanto, algumas pessoas cegas eram veneradas como profetas, consideradas como miraculosas, porque desenvolviam os outros sentidos com mais eficácia. Os definidos no contexto judaico-cristão, herdados pelo mundo ocidental, a cegueira era vista como castigo de Deus pelos pecados cometidos pelo individuo, por seus pais, seus avós ou por algum outro membro da família e, em alguns casos, quando voltava a enxergar diziam que era agraciada por Santa Luzia considerada protetora dos olhos. Na Idade Média, a cegueira, símbolo de trevas, era utilizada como castigo ou como ato de vingança. Ainda neste período era utilizada como pena judicial, aplicada como castigo para crimes nos quais havia participação dos olhos, como crimes contra a divindade e faltas graves às leis de matrimônio. A preocupação social dos religiosos com os deficientes visuais, data do século $\mathrm{V}$, quando se considera fundada, por São Lineu, na França, a primeira comunidade para cegos. Porém, a partir do século XVI, através do movimento renascentista, aconteceram muitas descobertas no campo científico, gerando mudanças e transformações ideológicas, sociais, econômicas e políticas, desdobrando-se em diversos setores da sociedade, fazendo com que as pessoas, médicos e religiosos começassem a significar de forma diferente as pessoas portadoras de alguma deficiência, como por exemplo a cegueira, e oferecer um tratamento mais humano e dar-lhes uma educação devida.

Segundo Mazzotta, (2011, apud Dupin; Silva, 2020) os primeiros movimentos educacionais para pessoas deficientes ocorreram na Europa. No Brasil, a educação é um direito fundamental assegurado pela Constituição Federal, desde 1988, que, em seu artigo 208, inciso III, dispõe:

O dever do Estado com a educação será efetivado mediante a garantia de: [...] atendimento educacional especializado aos portadores de deficiência, preferencialmente na rede regular de ensino. (Brasil, 1988, online apud Dupin; Silva, 2020).

Desde então, o processo de inclusão escolar de pessoas com deficiência está fundamentado em leis, decretos, portarias e na Lei de Diretrizes e Bases da Educação, Lei No 9394 de 20 de dezembro de 1996.

Segundo Anjos:

incluir na educação básica a pessoa com deficiência visual merece um olhar mais atento, mais minucioso, em face da possível rejeição do grupo para com essa pessoa, e assim, não podemos imaginar uma inclusão meramente ilusória, isso é, apenas colocar essa pessoa em meio aos outros, e deixar fluir naturalmente sua interação. (2021, online) 
Contudo, alguns aspectos particulares da inclusão de alunos com deficiência visual devem ser considerados para que haja sucesso no processo inclusivo, tais como salas de recursos, instrumentos e materiais pedagógicos adequados e, a relação entre aluno \& professor.

\section{Princípios Metodológicos}

Considerando as questões supracitadas, apresentamos no presente artigo pontos de reflexões sobre a inclusão escolar de alunos com deficiência visual, parcial ou total, pelo contexto histórico-sócio-cultural e legal da Educação Superior.

A metodologia utilizada para este estudo foi de um levantamento literário, tendo como campo de pesquisa os alunos da Educação Básica, portadores de deficiência visual, e o processo de inclusão escolar assegurados pela legislação vigente no Brasil.

Para tanto, foram selecionados estudos publicados em revistas especializadas, periódicos e trabalhos acadêmicos acerca da temática e de seus aspectos por nós considerados relevantes: cegueira, deficiência visual, educação especial, inclusão escolar e legislação, bem como em bases de dados como Pubmed, Scielo, Google Scholar, bibliotecas virtuais, entre outras.

\section{Cegueira, deficiência visual e o contexto histórico cultural}

A OMS define cegueira como uma perda parcial ou total da capacidade de ver do indivíduo, prejudicando a coleta e interpretação das informações por ele desejada. Diversos autores concordam que a visão é um dos sentidos mais utilizados na captação de informações, totalizando quase $80 \%$, o que nos remete a afirmação que é pela visão que o indivíduo tem a possibilidade de entender, compreender e interpretar o mundo a sua volta. (Santos, 2004; Oliveira, 1997 apud Parnof, 2010).

A deficiência visual adquirida é a que acontece no decorrer da vida seja pela evolução de alguma doença ocular congênita, ou por doença adquirida, pela velhice, ou por algum acontecimento externo, como um acidente, por exemplo. (Anjos, on-line)

A OMS, na Resolução SE n 246/86, define e classifica como portador de visão subnormal, ou baixa visão, aquele que possui acuidade visual entre 0,05 a 0,3 , em ambos os olhos, sendo acuidade visual a distância entre um ponto e outro, em uma linha reta. O processo educativo para essas pessoas se desenvolve por meios visuais, ainda que seja necessário a utilização de recursos específicos, como óculos, lupas, etc. Para os portadores de cegueira total, a acuidade visual deve ser inferior a 0,05 em ambos os olhos. (Anjos, on-line)

Contextualizando a cegueira na história da humanidade, faz-se necessário mencionar duas grandes correntes de pensamento que influenciaram todas as demais, inclusive a visão ocidental de indivíduo, sociedade e religião. Classen (1993) afirma que é na civilização grega antiga que foi estabelecida a divisão dos cinco sentidos, que até hoje é conhecida mundialmente (Classen, 1993 apud Martins, 2011). Aristóteles não apenas estabeleceu como hierarquizou ser a visão o sentido que é melhor desenvolvido e o mais necessário para a sobrevivência e vida do ser humano. (Synnot, 1993 apud Martins, 2011).

Classen (1993) defende que a oralidade usada na Grécia Antiga para transmitir conhecimentos facilitou a aprendizagem dos cegos e, por conseguinte, o seu desenvolvimento intelectual. Para as famílias abastadas, as que tinham melhor condição de vida, os cegos não eram marginalizados. Na cultura judaico-cristã a cegueira está compreendida na dicotomia entre luz e trevas, simbolizando ganância, ignorância, morte, pecado. Na Bíblia acrescenta-se o significado de punição de Deus pelos pecados. Conforme Winzer (1997 apud Martins, 2011), o texto de Levíticos apresenta orientações quanto aos cuidados com as pessoas com deformidades. Sendo esse exemplificado no momento em que o próprio Deus orienta todos a não amaldiçoar o surdo, nem por pedra de tropeço diante os cegos. 
Pois nenhum homem em quem houver alguma deformidade se chegará; como homem cego, ou coxo, ou de nariz chato, ou de membros demasiadamente compridos (...) porquanto defeito há nele, para que não profane os meus santuários; porque eu sou o senhor que os santifico. (Levítico2 21: 16-24 apud Martins, 2011).

Alguns autores exaltam as atitudes de Jesus em salvar os cegos e curá-los, declarando que o segundo mandamento das leis de Deus é amar ao próximo como a si mesmo, incluindo qualquer ser com ou sem deformidades. Ele não desconstrói o pensamento do Velho Testamento, mas sim cumpre o que Deus ordenada (Martins, 2011). Somente a partir do movimento renascentista, século XVI, que os avanços científicos começam desmistificar a cegueira, nos levando a dizer que aqui inicia o processo educacional de inclusão. Citamos alguns precursores, que segundo Dupin e Silva (2020) foram: Valentin Haüy, que fundou em Paris, no ano 1784, o Instituto Nacional dos Jovens Cegos, a primeira escola destinada à educação dos cegos e à sua formação profissional. O método adotado foi o do alfabeto em relevo para a leitura e de caracteres móveis para a escrita. A ideia surgiu após ele assistir a um espetáculo onde um empresário exibia dez cegos como fantoches na Feira de Santo Ovídio, Paris. (Lerparaver,2005 apud Dupin; Silva 2020); Charles Barbier desenvolveu um processo de escrita próprio para transmissão de mensagens no campo de batalha à noite de modo que não precisasse utilizar iluminação, evitando atrair a atenção dos inimigos. Tal processo de escrita codificada era expressa por pontos salientes, representando os trinta e seis sons básicos da língua francesa. A ideia de Barbier despertou o interesse de alguns professores e logo começou a ser utilizada pelos alunos internos no Instituto Nacional dos Jovens Cegos (Mazzota, 2011, p. 20 apud Dupin; Silva 2020). O estudante do Instituto, Louis Braille, que ficou cego aos três anos de idade quando brincava na oficina do pai ferindo um olho e, por consequência de uma infecção, acabou perdendo a visão do segundo olho, fez uma adaptação do código militar de comunicação noturna para as necessidades dos cegos, que foi denominada de sonografia e mais tarde de Método Braile (Lerparaver, 2005 apud Dupi; Silva, 2020) (Mazzota, 2011, p. 20 apud Dupin; Silva 2020).

Cabe ressaltar que o desenvolvimento do processo educacional para pessoas com deficiência começou na Europa, porém em caráter assistencialista e segregativo. Os estudantes tinham por destino as escolas especiais ou instituições que os mantinham na sua limitação, em vez de uma educação que considerasse as necessidades especiais de cada sujeito e tornando-os cidadãos plenos (Dupin \& Silva, 2020).

No Brasil, o atendimento a pessoas com deficiência teve início durante o império, com a criação de duas instituições: Instituto dos Meninos Cegos, o atual Instituto Benjamin Constant; e o Instituto dos Surdos-Mudos, hoje denominado Instituto Nacional de Educação de Surdos, INES (Miranda 2008 apud Santos; Vieira, on-line). Por fim, em 1988, a Constituição Federal assegura que a educação é direito fundamental de todos, firmando o compromisso de uma educação especializada as pessoas com qualquer tipo de deficiência.

\section{Legislação vigente de Educação Especial e Inclusão escolar}

Na legislação que versa sobre a temática, podemos destacar a Lei de Diretrizes e Bases da Educação Nacional, Lei nº 9.394/96; a Política Nacional da Educação Especial na Perspectiva da Educação Inclusiva (2008); as Diretrizes Nacionais para Educação Especial na Educação Básica (Resolução CNE/CEB No 2, de 11 de setembro de 2001); e a lei no 13.146/15 que institui a Lei Brasileira de Inclusão da Pessoa com Deficiência. (Santos; Vieira, on-line).

Em 1996, a Lei de Diretrizes e Bases da Educação Nacional (LDBEN), № 9.394, atualiza a concepção de ensino para as pessoas com necessidade educacional especial e estabelece um sistema equivalente à educação inclusiva, no capítulo $\mathrm{V}$, sessão da Educação Especial.

Currículos, métodos, técnicas, recursos educativos e organização, específicos para atender às suas necessidades; terminalidade específica para aqueles que não puderem atingir o nível exigido para a conclusão do ensino fundamental, em virtude de suas deficiências [...], professores com especialização adequada em nível médio ou 
superior, para atendimento especializado, bem como professores do ensino regular capacitados para a integração desses educandos nas classes comuns; educação especial para o trabalho, visando a sua efetiva integração na vida em sociedade, inclusive condições adequadas para os que não revelarem capacidade de inserção no trabalho competitivo, mediante articulação com os órgãos oficiais afins [...] acesso igualitário aos benefícios dos programas sociais suplementares disponíveis para o respectivo nível do ensino regular (Brasil, 1996, p. 19-20 apud Santos; Vieira, online ).

O Brasil, objetivando a educação inclusiva, criou a Política Nacional de Educação Especial na Perspectiva da Educação Inclusiva, portaria n ${ }^{\circ}$ 555/2007, prorrogada pela portaria 948/2007. (Brasil, 2008, p.15 apud Santos; Vieira, online), que segue orientando:

[...] acesso ao ensino regular, com participação, aprendizagem e continuidade nos níveis mais elevados do ensino; transversalidade da modalidade de educação especial desde a educação infantil até a educação superior; oferta do atendimento educacional especializado; formação de professores para o atendimento educacional especializado e demais profissionais da educação para a inclusão; participação da família e da comunidade; acessibilidade arquitetônica, nos transportes, nos mobiliários, nas comunicações e informação; e articulação intersetorial na implementação das políticas públicas (Brasil, 2008, p. 15 apud Santos; Vieira, on-line ).

O acesso e a permanência da criança com necessidade educacional especial no ensino regular são fundamentais para sua aprendizagem, implicando na sua participação ativa no meio em que está inserido. Este direito está assegurado na Lei Brasileira de Inclusão da Pessoa com Deficiência, Estatuto da Pessoa com Deficiência, Lei No 13.146/2015, que fundamenta e embasa as ações inclusivas, objetivando a igualdade e o exercício dos direitos como ser humano. Sobre o direito a educação, o Artigo 28 esclarece que compete ao poder público assegurar, criar, desenvolver, implementar, incentivar, acompanhar e avaliar questões relacionadas a ações inclusivas.

Nesse sentido, são destacadas algumas exposições do artigo:

II - aprimoramento dos sistemas educacionais, visando a garantir condições de acesso, permanência, participação e aprendizagem, por meio da oferta de serviços e de recursos de acessibilidade que eliminem as barreiras e promovam a inclusão plena; III - projeto pedagógico que institucionalize o atendimento educacional especializado, assim como os demais serviços e adaptações razoáveis, para atender às características dos estudantes com deficiência e garantir o seu pleno acesso ao currículo em condições de igualdade, promovendo a conquista e o exercício de sua autonomia; VI pesquisas voltadas para o desenvolvimento de novos métodos e técnicas pedagógicas, de materiais didáticos, de equipamentos e de recursos de tecnologia assistiva; IX - adoção de medidas de apoio que favoreçam o desenvolvimento dos aspectos linguísticos, culturais, vocacionais e profissionais, levando-se em conta o talento, a criatividade, as habilidades e os interesses do estudante com deficiência; XVIII - articulação intersetorial na implementação de políticas públicas (Brasil, 13.146/15 apud Santos; Vieira, online).

A legislação vigente garante o processo inclusivo, porém cabe a todos os envolvidos, educadores, pais e sociedade, responsabilizar-se em romper barreiras, dialogar e não desistir de incluir o deficiente visual no âmbito escolar, pois a sua inclusão possui alguns aspectos particulares que precisam ser observados a nível governamental, familiar, escolar e sociedade.

\section{Alguns aspectos do processo inclusivo de deficientes visuais: parcial ou total}

A educação de pessoas com deficiência visual tem sido tema de grandes discussões atualmente. Tanto educadores, como familiares, acreditam que o melhor para os educandos é uma escola especializada (equipada e preparada), uma vez que os educadores não estão capacitados para receber esses alunos, bem como as escolas regulares não possuem equipamentos necessários e adequados para garantir uma aula de qualidade. (Santos, 2008).

Segundo Santos (2008): 
Alunos com deficiência visual devem ser educados como todos os demais, frequentando uma escola regular e convivendo com os mais variados alunos para que aprendam juntos a conviver com a limitação um do outro, considerando que todos nós temos algum tipo de "deficiência", ou seja, dificuldade.

Há que se reconhecer os desafios, mas entendemos que o sucesso depende do empenho do professor, do aluno, dos familiares e gestores, que juntos deverão estar em permanente diálogo, para traçarem perspectivas e objetivos a cada conteúdo, atividade e avaliação.

Um aspecto considerado importante para o suporte necessário ao aluno deficiente visual, em escolas regulares, é que a escola tenha uma sala de recursos especiais para que seja um complemento para sanar dúvidas e dificuldades encontradas por ele na sala de aula regular. Essa sala deve ser uma extensão da sala regular, contendo materiais e equipamentos especializados, profissional capacitado que domine o sistema Braille e os instrumentos necessários à educação inclusiva. Outro aspecto acatado é a existência do apoio dado pelo professor especializado durante as aulas regulares e que atue na sala de recursos fazendo o elo entre aluno, família e a escola. Por fim, cabe ao professor de apoio na sala regular, ou na sala especializada, multiplicar conhecimentos; esclarecer dúvidas dos conteúdos apresentados pelos professores durante as aulas; assistir às aulas com a turma; colaborar na elaboração de materiais didáticos compatíveis com as necessidades dos alunos; participar ativamente com o professor regular na preparação de exercícios e avaliações para manter a equidade entre os alunos; desenvolver juntamente com o coordenador pedagógico da escola, e com o professor da sala regular, um trabalho de orientação aos pais, informando-os acerca do progresso educacional de seus filhos e os métodos utilizados, fazendo com que a proposta pedagógica da escola seja inclusiva. (Santos, 2008) Alguns materiais utilizados pelos deficientes visuais, tais como, máquinas Braille, regletes (instrumento comum para escrita em braille), impressoras Braille, lupas eletrônicas e manuais, softwares com síntese de voz para desktop e notebooks (para leitura e confecção de atividades), livros em Braille ou em letras ampliadas são imprescindíveis na sala de recursos especiais.

Segundo Santos (2208), as principais condições que precisam ser observadas pelos professores no dia-a-dia com os alunos deficientes visuais são: estabelecer constantes diálogos; não pôr diferenças entre os alunos; não ter receio de utilizar expressões que fale sobre a falta de visão; não tratar o aluno em inclusão com diferença alguma; não se admirar com conquistas que não eram esperadas; evitar gesticular ou apontar coisas no quadro-negro, dizendo isto ou aquilo; avisar verbalmente quando for sair de classe; a entrada de cães-guia é permitida e assegurada por lei.

A inclusão de alunos deficientes visuais, parcial ou total, nas Universidades é uma realidade possível por todos os envolvidos neste processo desde que haja preparo de toda equipe envolvida.

\section{Considerações Finais}

Pode-se concluir que o processo inclusivo educacional é uma realidade que enfrenta grandes desafios, mas que está sendo construída verdadeiramente.

É muito importante os alunos cegos, ou deficientes visuais, percebam que a principal barreira para a inclusão, está sendo extinta. Com o avanço da ciência e o esclarecimento de toda a sociedade, por meio das mídias, acerca do problema físico, a cegueira ou baixa visão, está sendo desmistificada.

Hoje no Brasil há inúmeras leis que versam sobre a temática e garantem equidade no sistema educacional. Nesse contexto, muitos deficientes visuais deixaram de ir para as instituições especiais e estão sendo matriculados em escolas regulares, apesar de ainda haver dificuldades por parte de educadores e gestores, e receio dos familiares pela rejeição e discriminação que seus filhos podem passar. 
Apesar da educação de deficientes visuais possuir alguns aspectos particulares, a persistência, qualificação do educador e gestor, o apoio familiar e políticas públicas eficiente, podem desenvolver aprendizagens normalmente se tornando cidadãos críticos e benfeitores para o desenvolvimento da humanidade.

\section{Referências}

Arelaro, L.R. G. (2003) Direitos Sociais e Política Educacional: alguns ainda são mais iguais que outros. Políticas Públicas: Educação, Tecnologias e Pessoas com Deficiência. Campinas: Mercado das Letras/Associação de Leitura do Brasil.

Alberti, V. (2004) Manual da história oral, Editora FGV

Alves M, A.J ; \& Gewandsznajder, F. (1998). O método nas ciências naturais e sociais - Pesquisa quantitativa e qualitativa. São Paulo: Pioneira

André, M. E. D. A. (1995). Etnografia da prática escolar, Papirus

Anjos, A. D. $O$ aluno cego e de baixa visão no meio escolar. Revista Brasil Escola. Meu artigo. UOL.com.br. online. https://meuartigo.brasilescola.uol.com.br/educacao/o-aluno-cego-baixa-visao-no-meio-escolar.htm.

Brasil. Ministério da Justiça. (1997). Declaração de Salamanca e linha de ação sobre necessidades educativas especiais (2.ed.) Brasília: Corde.

Brasil, LDB. Lei 9394/96 - Lei de Diretrizes e Bases da Educação Nacional. Disponível em < http://www.planalto.gov.br/ccivil_03/leis/L9394.htm>.

Caiado, K. R. M. (2005). Histórias de vida e deficiência: reflexões sobre essa abordagem de pesquisa. In: Jesus, D.M. (Org.) Pesquisa e educação especial: mapeando produções. Vitória: EDUFES.

Cerqueira, J. B.; \& Ferreira, M. A. (2000). Os recursos didáticos na educação especial. Rio de Janeiro: Revista Benjamin Constant.

Dupin, A. P. S. Q. \& Silva, M. O. da. Educação Especial e Legislação brasileira: revisão de literatura. Scientia Vitae. Edição especial. Vol 10. No 29. p. 65. 2020. Disponível em :<http://revistaifspsr.com/v10n297690.pdf >.

Grifing, H. C. \& Gerber, P. J. Desenvolvimento tátil e suas implicações na educação de crianças cegas. Rio de Janeiro: Revista Benjamin Constant, 5.

Katz, D. The world of touch. L. E. Krueger (trans.), Hillsdale, N.J., Erlbaum

Lederman, S.J. \& Klatzky, R. L. Hand movements: a window into haptic object recognition. Cognitive Psychology: General, 114: 342-368, 1987. Lima, F.J. Representação mental de estímulos táteis. (Dissertação de Mestrado) - Faculdade de Filosofia, Ciências e Letras de Ribeirão Preto - Universidade de São Paulo. Ribeirão Preto. p.166.

Lima, E. C. (2016). A inclusão da criança com deficiência visual na escola regular. Fundação Dorina Nowill para Cegos. https://fundacaodorina.org.br/blog/artigo-a-inclusao-da-crianca-com-deficiencia-visual-na-escola-regular/

Matins, B. S. (2011). Lugares da Cegueira: Portugal e Moçambique no trânsito de sentidos. Sobreadeficienciavisual. http://www.deficienciavisual.pt/rSignificados_ancestrais_cegueira.htm.

Odorina, Fundação. Estatísticas da deficiência visual. 2021.www.fundaçãoodrina. org.br. https://fundacaodorina.org.br/a-fundacao/deficienciavisual/estatisticas-da-deficiencia-visual/

Parnof, D. (2010). Deficiência Visual: a Perda $e \quad a \quad$ Superação. Instituto Benjamin http://www.ibc.gov.br/images/conteudo/revistas/benjamin_constant/2010/edicao-45-abril/Nossos_Meios_RBC_RevAbr2010_Artigo_3.doc Deficiência Visual: a Perda e a Superação Deisy Parnof.

Santos, F. (2008). A inclusão dos deficientes visuais na escola regular. Sobre a deficiência visual. In Educação Inclusiva. http://www.deficienciavisual.pt/txtinclusao_DV_escola_regular.htm.

Silva, S. (2003). A política educacional brasileira e as pessoas com deficiências, como difundir o discurso de uma política pública de direitos e praticar a privatização. In: Vizim, M.; Silva, S. (Org.). Políticas Públicas: educação, tecnologias e pessoas com deficiência. Campinas: Mercado das Letras/Associação de Leitura do Brasil.

Triviños, A. N. S. I. (1987). Introdução a pesquisa em ciências sociais: a pesquisa qualitativa em educação. Atlas.

Unesco. Declaração Mundial sobre Educação para Todos: satisfação das necessidades básicas de aprendizagem. Tailândia, Jomtien (1990). Disponível em: http://unesdoc.unesco.org 